\title{
Article \\ Assessment and Prediction Model of GFRP Bars' Durability Performance in Seawater Environment
}

\author{
Wenchao $\mathrm{Li}^{1,2}{ }^{1}$, Fusheng Wen ${ }^{2}$, Min Zhou ${ }^{3}$, Fusheng Liu ${ }^{1, *}$, Yuzhao Jiao ${ }^{4}$, Qingfeng $\mathrm{Wu}^{2}$ and Hengan Liu ${ }^{1}$ \\ 1 College of Water Conservancy and Civil Engineering, Shandong Agricultural University, Taian 271018, China; \\ liwch@tsu.edu.cn (W.L.); 18369293016@163.com (H.L.) \\ 2 College of Mechanical and Architectural Engineering, Taishan University, Taian 271000, China; \\ win1490659134@163.com (F.W.); wuqingfeng2022@163.com (Q.W.) \\ 3 School of Science, North University of China, Taiyuan 030051, China; zhoumin@nuc.edu.cn \\ 4 Shandong Safety Industrial Co., Ltd., Taian 271000, China; kjfzb@sftsy.com \\ * Correspondence: liufsh@sdau.edu.cn
}

Citation: Li, W.; Wen, F.; Zhou, M.; Liu, F.; Jiao, Y.; Wu, Q.; Liu, H. Assessment and Prediction Model of GFRP Bars' Durability Performance in Seawater Environment. Buildings 2022, 12, 127. https://doi.org/ 10.3390 /buildings12020127

Academic Editors: Klára Kobetičová and Martin Böhm

Received: 4 December 2021

Accepted: 20 January 2022

Published: 26 January 2022

Publisher's Note: MDPI stays neutral with regard to jurisdictional claims in published maps and institutional affiliations.

Copyright: (C) 2022 by the authors. Licensee MDPI, Basel, Switzerland. This article is an open access article distributed under the terms and conditions of the Creative Commons Attribution (CC BY) license (https:// creativecommons.org/licenses/by/ $4.0 /$ )

\begin{abstract}
In this study, the performance degradation law and mechanism of glass fiber reinforced polymer (GFRP) bars were investigated by being immersed in natural seawater (denoted as SW), saline-alkali solution (SA), or wrapped with concrete, and then submerged in natural seawater (SWC). A series of short-beam shear tests were conducted to investigate the effects of aging temperature and time on the interlaminar shear strength (ILSS) of GFRP bars. Microstructure changes, glass transition temperature $\left(\mathrm{T}_{\mathrm{g}}\right)$ difference, and hydrolysis degree of GFRP bars after aging in three environments for 183 days were analyzed using scanning electron microscopy (SEM), differential scanning calorimeter (DSC), and Fourier transform infrared spectroscopy (FTIR). Test results demonstrated that the temperature could accelerate the strength degradation of GFRP bars significantly. After 183-day aging treatment at $60{ }^{\circ} \mathrm{C}$, the ILSS retention rates of GFRP bars in the three environments of SW, SWC, and SA were $66.41 \%, 53.10 \%$, and $45.36 \%$, respectively; and $\mathrm{T}_{\mathrm{g}}$ was $1.7 \%, 7.0 \%, 7.8 \%$ lower than that of unconditioned sample, respectively. Meanwhile different degrees of damage, such as separation between fiber and resin and few holes in the resin, were observed on the GFRP bars in the SWC and SA environments. It was also found that irreversible hydrolysis took place in some resins. The durability prediction model of GFRP bars serving in the Yellow Sea of China was established by using Arrhenius equation, and the correlation coefficient with the test data was not less than 0.94.
\end{abstract}

Keywords: GFRP bars; seawater; interlaminar shear strength; the glass transition temperature; microstructure; hydrolysis; prediction model

\section{Introduction}

It is a common engineering problem that chloride ions in marine environments penetrate through the concrete protective layer to rust rebars, which greatly jeopardizes their structural safety and durability. Coating rebars with protective shells (e.g., epoxy and galvanizing) is a common method to improve their ability to resist corrosion; However, the drawbacks, such as complex production process, poor anti-corrosion effect, and high costs, limits its application, especially in marine environment [1,2]. As one of the effective substitutes for rebars in marine engineering, GFRP bars are composed of continuous glass fiber and resin, featuring great corrosion resistance, high tensile strength, and light weight. Currently, GFRP bars have been widely used in coastal wave walls, barrier board, and marine loading platforms [3]. Despite the advantage of corrosion resistance, GFRP bars cause microstructure damage and macro-mechanical property decline when used in a high alkali solution of concrete and seawater environment for a long time $[4,5]$, which can be chiefly attributed to the damage of service environment to glass fiber, resin, and their interface phase [6,7]. Scholars usually place GFRP bars in different environments for accelerated aging test to explore the degradation law of long-term mechanical properties 
of GFRP bars. Alkali solution, saline solution, and neutral solution are commonly used to simulate the internal alkali environment of the concrete, the seawater environment, and the freshwater environment, respectively. The durability deterioration of GFRP bars in freeze-thaw and dry-wet cycling conditions was also investigated to estimate the environmental influences on GFRP reinforced concrete members. Manalo et al. [8] pointed out that, under the same temperature conditions, the degradation speed of the ILSS of GFRP bars was alkaline solution, tap water, and saline solution, in order from fast to slow. The strength retention rate of GFRP bars in real concrete environments were higher than that in simulated concrete pore solution environment. Benmokrane [9] put the GFRP bars based on polyester, vinyl-ester and epoxy resin in the alkali environment at $60{ }^{\circ} \mathrm{C}$ and tested them after accelerated aging for $5000 \mathrm{~h}$, indicating that the physical and mechanical properties of GFRP bars of vinyl-ester and epoxy resin decreased less after accelerated aging, compared to GFRP bars of polyester resin. This phenomenon has been explained by Chen [10], that when free $\mathrm{OH}^{-}$and water molecules diffuse in GFRP bars, they will produce a chemical reaction with esters groups in resin matrix, resulting in degradation of GFRP bars. Among the three categories of resins commonly used in engineering, polyester resin with maximum ester groups embodies the most significant degradation effect. Koller et al. [11] investigated the freeze-thaw resistance of GFRP bars ranging from $-29^{\circ} \mathrm{C}$ to $20{ }^{\circ} \mathrm{C}$ and indicated that freeze-thaw reduced the ultimate tensile strength of GFRP bars by no more than $10 \%$.

In recent years, researchers have studied the durability of GFRP bars in the marine environment. Robert et al. [12] simulated seawater by using salt solution with a concentration of $3 \%$, and placed GFRP bars wrapped by concrete in the simulated seawater and tap water environment, respectively. It was found that the resin matrix of GFRP bars had a great impact on their durability. In view of offshore engineering exposed to the alternating action of seawater wet-dry environment, Al-Salloum et al. [6] tested GFRP bars in $50{ }^{\circ} \mathrm{C}$ seawater with dry-wet cycle. They reported that after aging for 18 months, the tensile strength of GFRP bars lost $9.8 \%$. Morales et al. [13] used seawater instead of fresh water to produce concrete; that is, seawater concrete. They used seawater concrete to wrap the GFRP bars, and accelerated aging in seawater at $60^{\circ} \mathrm{C}$, based on an exponential degradation model. The retention rate of the tensile strength of GFRP bars was 72\%. Khatibmasjedi et al. [14] embedded GFRP bars in seawater concrete and immersed them in seawater at $60{ }^{\circ} \mathrm{C}$. After 24 months of aging, the tensile strength decreased by $21-26 \%$.

In addition to the above-mentioned macro-mechanical properties of GFRP bars, researchers have utilized SEM, FTIR, and DSC to observe the effects on the microstructure damage [8,14], chemical composition change [15], and $\mathrm{T}_{\mathrm{g}}$ of GFRP bars [16] caused by aging environments. The separation of fiber and resin of GFRP bars in seawater-contaminated concrete was reported by El-Hassan et al. [7], especially at high temperature. Fergani et al. [15] indicated that $\mathrm{OH} / \mathrm{CH}$ was an effective index to reflect the degree of degradation of GFRP bars. Montaigu et al. [16] analyzed $\mathrm{T}_{\mathrm{g}}$ changes of GFRP in alkali environments at $60{ }^{\circ} \mathrm{C}$ by DSC test technology, indicating that after 183-day aging, the $\mathrm{T}_{\mathrm{g}}$ of unsaturated resin-based GFRP decreased by approximately $6 \%$.

Based on the decline of macro-mechanical properties and micro tests, researchers put forward durability models suitable for different environments based on Arrhenius equation. In the prediction model proposed by Bank et al. [17], the linear relationship between the strength retention of fiber-reinforced-polymer (FRP) bars after aging and the logarithm of aging time appears in this model. Then, this model was applied by many researchers to predict the durability of FRP bars [18,19]. Some researchers used an exponential relationship to describe the relationship between the strength retention of FRP bars and aging time $[20,21]$, and it is assumed that the degradation of mechanical properties of FRP bars caused the separation of the fiber and resin interface.

The purpose of this study was to attempt to analyze the durability of GFRP bars cured in natural seawater, artificial saline-alkali solution, and concrete environments. The effects of temperature $\left(25,40\right.$, and $\left.60^{\circ} \mathrm{C}\right)$ and aging time $(15,30,60,90$, and 183 days) were 
investigated. Additionally, the study aimed to analyze the degradation law of mechanical properties of GFRP bars under different test conditions by ILSS, and to explain the degradation mechanism of GFRP bars by SEM, DSC, and FTIR. Ultimately, a prediction model of long-term mechanical properties of GFRP bars in seawater environment was proposed.

\section{Experimental Program}

\subsection{Materials}

In this test, GFRP bars were produced by Shandong Safety Industrial Co., Ltd., with the diameter of $16 \mathrm{~mm}$ and the fiber content of about $80 \%$. The bars were cut into 156 specimens with a length of $80 \mathrm{~mm}$.

\subsection{Aging Environment}

In this study, GFRP bars were treated in three ways. The GFRP bar specimens were directly placed in natural seawater taken from the Yellow Sea of China, with measured $\mathrm{pH}$ value of 8 , and this environment was recorded as SW. Moreover, according to CSA807 [22], $118.5 \mathrm{~g} \mathrm{Ca}(\mathrm{OH})_{2}, 4.2 \mathrm{~g} \mathrm{KOH}$, and $0.9 \mathrm{~g} \mathrm{NaOH}$ were added to $1 \mathrm{~L}$ deionized water, and the measured $\mathrm{pH}$ value of the acquired solution was about 13 . The alkali solution, used to simulate the concrete pore solution, was added with sodium chloride to make the chloride ion content 3.5\%, which was recorded as SA environment. The GFRP bars wrapped with concrete were immersed in natural seawater, and this environment was denoted as SWC. The thickness of concrete wrapped outside the GFRP bars was $20 \mathrm{~mm}$ to simulate the thickness of concrete protective layer. Then, the samples were placed in the incubator for accelerated aging, as is shown in Figure 1.

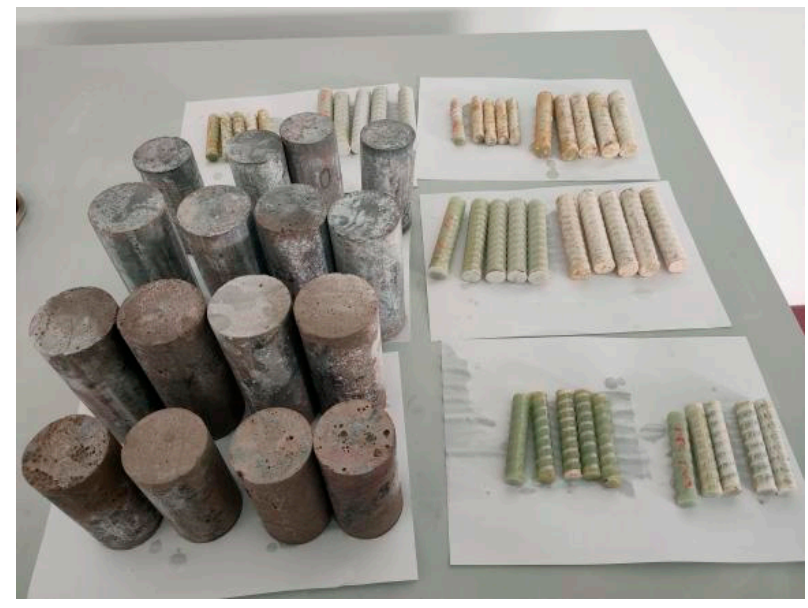

Figure 1. Specimens.

\subsection{Test Method}

The ILSS was measured by short-beam shear test. The short-beam shear test was carried out by the WAW-1000D electro-hydraulic servo universal testing machine, and according to ASTM D4475 [23]. The span was set as $48 \mathrm{~mm}$, as shown in Figure 2. Loading rate was set as $1.3 \mathrm{~mm} / \mathrm{min}$. The ILSS was calculated according to Equation (1) [23].

$$
S=0.849 P / d^{2},
$$

where $S$ is ILSS, $\mathrm{N} / \mathrm{m}^{2} ; P$ is breaking load, $\mathrm{N}$; and $d$ is diameter of specimen, $\mathrm{m}$. 




Figure 2. Short-beam shear test.

\section{Results and Discussion}

\subsection{Test Results}

Specimens that reached the specified aging time were taken out for test. Among them, the specimens were aged for 183 days in three environments at $60{ }^{\circ} \mathrm{C}$, with the surface morphologies shown in Figure 3. Comparison shows that SW environment imposed slight surface damage to GFRP bars. SWC environment caused serious damage to the resin on the surface of GFRP bars, leaving fibers separated from resin and some fibers on the surface fractured. SA environments contained a large amount of calcium hydroxide, which is slightly soluble in water, making calcium hydroxide precipitate on the surface of GFRP bars and penetrate to a certain depth.

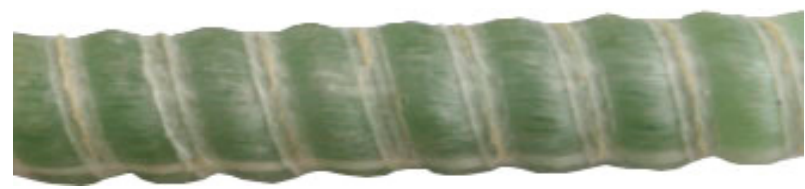

(a)

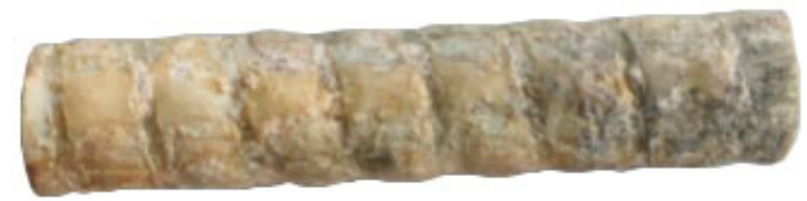

(b)

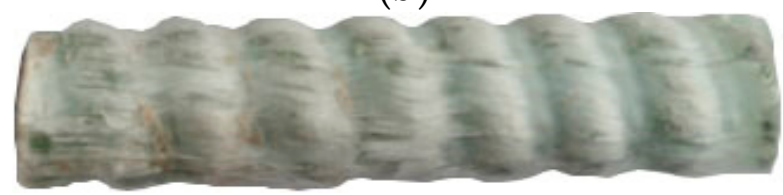

(c)

Figure 3. Surface morphology of GFRP bars after aging in different environments at $60{ }^{\circ} \mathrm{C}$ for 183 days: (a) SW; (b) SA; and (c) SWC.

The average ILSS of the unconditioned bars was $46.93 \mathrm{MPa}$. ILSS retention rate listed in Table 1 is the ratio of the ILSS of the aging sample and unconditioned bars. The test results are collected in Table 1. 
Table 1. ILSS retention (\%).

\begin{tabular}{cccccccccc}
\hline & \multicolumn{3}{c}{ SW } & \multicolumn{3}{c}{ SWC } & \multicolumn{3}{c}{ SA } \\
\hline & $\mathbf{2 5}{ }^{\circ} \mathbf{C}$ & $\mathbf{4 0}^{\circ} \mathbf{C}$ & $\mathbf{6 0}^{\circ} \mathbf{C}$ & $\mathbf{2 5}^{\circ} \mathbf{C}$ & $\mathbf{4 0}{ }^{\circ} \mathbf{C}$ & $\mathbf{6 0}^{\circ} \mathbf{C}$ & $\mathbf{2 5}{ }^{\circ} \mathbf{C}$ & $\mathbf{4 0}{ }^{\circ} \mathbf{C}$ & $\mathbf{6 0}^{\circ} \mathbf{C}$ \\
\hline $15 \mathrm{~d}$ & 98.53 & 97.10 & 94.41 & 97.82 & 96.70 & 92.93 & 95.93 & 95.53 & 90.16 \\
$30 \mathrm{~d}$ & 98.21 & 95.97 & 89.94 & 96.58 & 94.93 & 87.04 & 93.23 & 92.45 & 81.45 \\
$60 \mathrm{~d}$ & 95.93 & 93.93 & 83.25 & 94.37 & 91.23 & 76.58 & 87.22 & 85.45 & 70.80 \\
$90 \mathrm{~d}$ & 94.76 & 92.33 & 75.46 & 92.37 & 88.05 & 68.27 & 81.84 & 77.94 & 61.66 \\
$183 \mathrm{~d}$ & 91.82 & 86.62 & 66.41 & 89.16 & 80.22 & 53.10 & 78.25 & 68.73 & 45.36 \\
\hline
\end{tabular}

\subsection{Analysis of ILSS Retention of GFRP Bars}

Figure 4 shows ILSS retention of GFRP bars in three environments. It can be seen from Table 1 and Figure 4 that the ILSS retention of GFRP bars decreases under three environments of SW, SWC, and SA. At the same temperature and aging time, the ILSS decline of GFRP bars was the largest in SA environment, followed by SWC environment, and the least in SW environment. Taking accelerated aging at $60^{\circ} \mathrm{C}$ for 183 days as an example, the ILSS retention of GFRP bars in SA, SWC, and SW were $45.36 \%, 53.10 \%$, and $66.41 \%$, respectively. It was indicated that the long-term evaluation of ILSS retention of GFRP bars was conservative by using the simulated concrete pore solution in SA environment given in literature [22]. The corrosion of GFRP bars in SWC environment was slighter than that in SA environment. The main reason was that concrete effectively prevents $\mathrm{OH}^{-}$and water molecules from reacting with GFRP bars. The strength retention of GFRP bars in SW environments were higher than those in SWC and SA environments, indicating that alkaline environments were more likely to cause degradation of GFRP bars. Similar laws could be obtained at the other two temperatures.

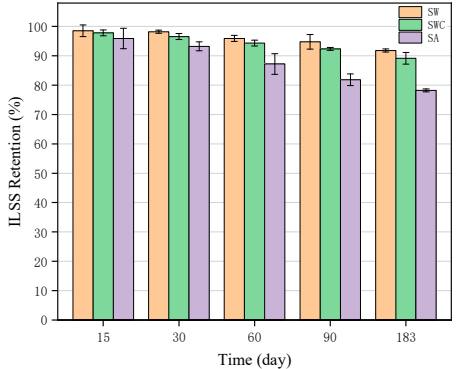

(a)

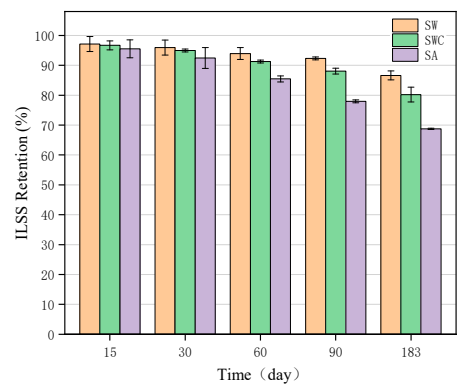

(b)

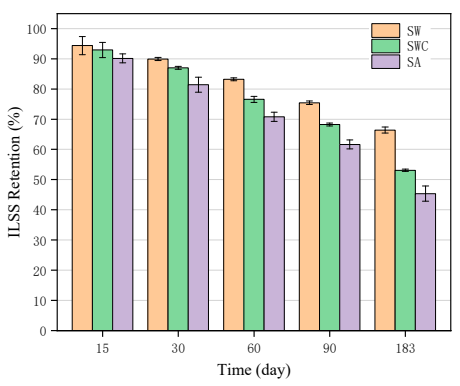

(c)

Figure 4. Comparison of ILSS retention of GFRP bars in three environments: (a) $25^{\circ} \mathrm{C}$; (b) $40^{\circ} \mathrm{C}$; (c) $60{ }^{\circ} \mathrm{C}$.

Figure 5 shows the influence of aging temperature on the strength retention of GFRP bars. Under the three environments, the decline rate of ILSS retention of GFRP bars increased with the temperature. After accelerated aging for 183 days in SWC environment, the ILSS decreased by $10.84 \%, 19.78 \%$, and $46.90 \%$, at $25^{\circ} \mathrm{C}, 40^{\circ} \mathrm{C}$, and $60^{\circ} \mathrm{C}$, respectively. The main reason for this phenomenon was that the increase of temperature can accelerate the hydrolysis reaction rate of GFRP bars and reduce the macro-mechanical properties. It was found that the strength of GFRP bars declined rapidly in the early stage. Taking GFRP bars cured in the SWC aging environment as an example, the ILSS at $25{ }^{\circ} \mathrm{C}, 40$ ${ }^{\circ} \mathrm{C}$, and $60{ }^{\circ} \mathrm{C}$ decreased by $7.63 \%, 11.95 \%$, and $31.73 \%$, respectively, from 0 to 90 days, and decreased by $3.21 \%, 7.83 \%$, and $15.17 \%$, respectively, from 90 days to 183 days. It illustrated that within almost the same aging time, the strength degradation in the later stage equals only $1 / 3$ to $2 / 3$ of that in the earlier stage. 


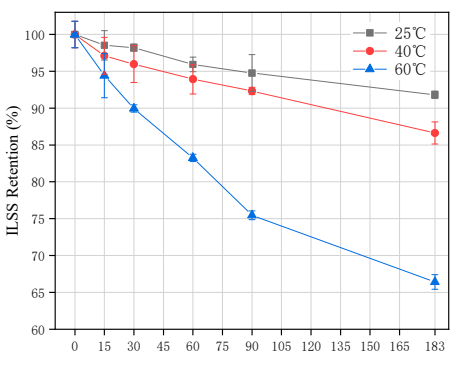

(a)

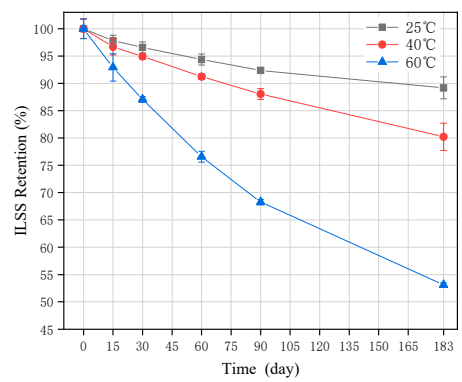

(b)

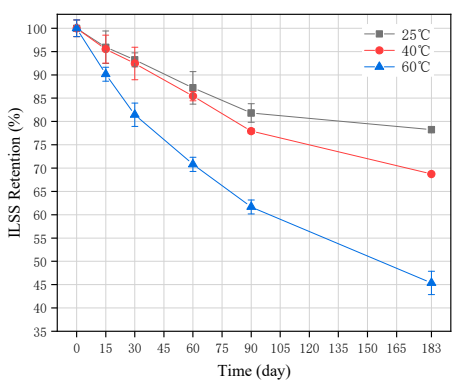

(c)

Figure 5. Comparison of ILSS retention of GFRP bars in three temperatures: (a) SW; (b) SWC; and (c) SA.

\section{Accelerated Aging Mechanism of GFRP Bars}

\subsection{SEM}

Figure 6 shows the microstructures of the samples with accelerated aging for 183 days in three environments at $60^{\circ} \mathrm{C}$. GFRP bars were composed of fiber, resin, and their interface phase, and sample aging was closely related to these components [6]. From Figure 6a, it can be concluded that GFRP bars in the SW environment do not suffer conspicuous damage, whereas samples in SWC and SA environments show different degrees of separation between the fiber and the resin. This phenomenon is caused by different expansion degrees of resin matrix after water absorption in different environments, and the seepage pressure will also destroy the interface phase.

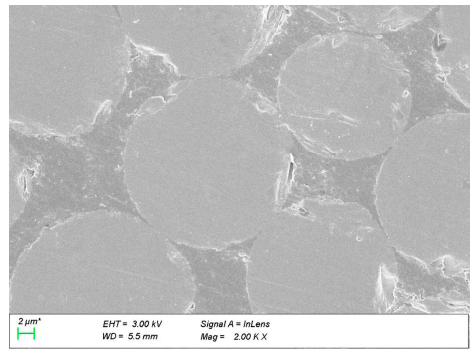

SW

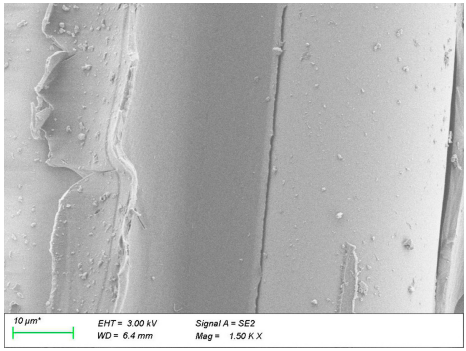

SW

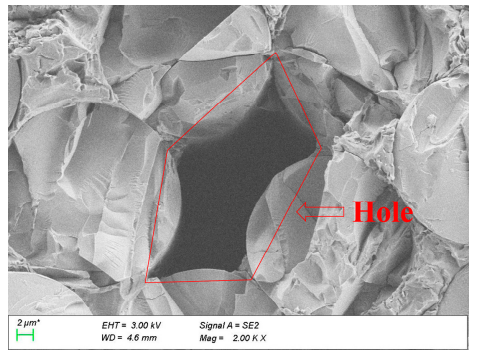

SA

(a)

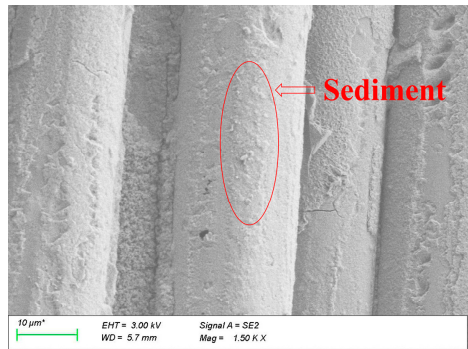

SA

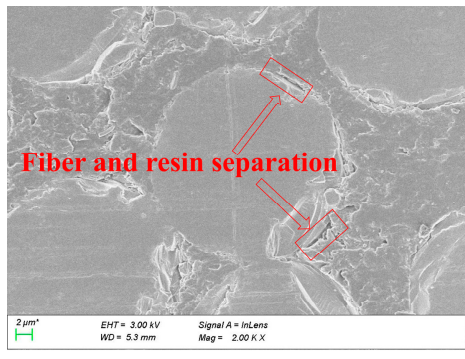

SWC

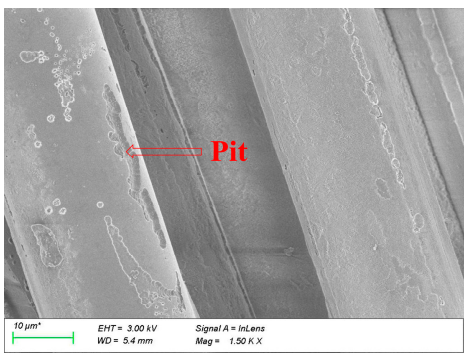

SWC

(b)

Figure 6. SEM photos of GFRP bars aged at $60^{\circ} \mathrm{C}$ for 183 days: (a) Cross section; (b) Longitudinal section.

A few holes were found in the resin of samples in SA environment due to the erosion effect of $\mathrm{OH}^{-}$on the resin. It is shown in Figure $6 \mathrm{~b}$ that fiber surfaces of samples aged in SW environment were smooth and suffered slight damage. After aging in SA environment, the fiber surfaces of samples were surrounded by sediments. There were shallow pits on the fiber surface of the sample after aging in the SWC environment. A large amount 
of $\mathrm{OH}^{-}$in SA and SWC environments reacted with $\mathrm{SiO}_{2}$ in the glass fiber according to Equation (2) [24]. The product $\mathrm{Si}-\mathrm{OH}$, a gel layer, was attached to the surface of the fiber, and its density was less than that of the fiber, which increased the $\mathrm{OH}^{-}$diffusion rate. In SW environment, the hydrolysis reaction expressed by Equation (3) occurred first [24], and then the generated product, $\mathrm{OH}^{-}$, reacted with $\mathrm{SiO}_{2}$ provided by fiber. Therefore, the reaction rate in SW environment was lower than that in SA and SWC environments, leading to slighter destruction of the surface of fibers.

$$
\begin{aligned}
& \mathrm{Si}-\mathrm{O}-\mathrm{Si}+\mathrm{OH}^{-} \rightarrow \mathrm{Si}-\mathrm{OH}+\mathrm{Si}-\mathrm{O}^{-} \\
& \mathrm{Si}-\mathrm{O}-\mathrm{Na}+\mathrm{H}_{2} \mathrm{O} \rightarrow \mathrm{Si}-\mathrm{OH}+\mathrm{NaOH}
\end{aligned}
$$

Based on the results of macro-mechanical properties and microstructure observation, the degradation mechanism of GFRP bars was analyzed as follows:

(1) Under the action of water molecules and $\mathrm{OH}^{-}$, the resin matrix expands and deforms to varying degrees, which weakens the bond with the fiber. Seepage pressure will further destroy the interface phase.

(2) The fiber degrades in alkaline solution due to the reaction between $\mathrm{OH}^{-}$and $\mathrm{SiO}_{2}$ in the glass fiber.

(3) The hydrolysis reaction of ester bond in resin matrix will also reduce the property of GFRP bars. In this study, a small amount of resin damage was observed. This is because the vinyl-ester resin used to manufacture GFRP bars contains a few ester bonds.

\subsection{DSC and FTIR}

According to ASTM D3418 [25], The $\mathrm{T}_{\mathrm{g}}$ of GFRP bars aged at $60^{\circ} \mathrm{C}$ for 183 days was measured by DSC. In order to eliminate the influence of thermal history, the temperature was raised 250 and lowered 50 twice. The $\mathrm{T}_{\mathrm{g}}$ measured at the two temperature rise processes were denoted as $\mathrm{T}_{\mathrm{g} 1}$ and $\mathrm{T}_{\mathrm{g} 2}$, respectively, as shown in Table 2.

Table 2. The $\mathrm{T}_{\mathrm{g}}$ of GFRP bars in different environments.

\begin{tabular}{ccccc}
\hline \multirow{2}{*}{ Environment } & \multirow{2}{*}{ Temperature $\left({ }^{\circ} \mathbf{C}\right)$} & Aging Time (Day) & \multicolumn{2}{c}{$\mathbf{T}_{\mathbf{g}}\left({ }^{\circ} \mathbf{C}\right)$} \\
\cline { 3 - 5 } & & & $\mathbf{T}_{\mathbf{g} \mathbf{y}}$ & $\mathbf{T}_{\mathbf{g} 2}$ \\
\hline Unconditioned & - & - & 113 & 115 \\
SW & 60 & 183 & 105 & 113 \\
SA & 60 & 183 & 102 & 106 \\
SWC & 60 & 183 & 102 & 107 \\
\hline
\end{tabular}

As shown in Figure $7, \mathrm{~T}_{\mathrm{g} 2}$ of all samples are greater than $\mathrm{T}_{\mathrm{g} 1}$. Compared with unconditioned samples, $\mathrm{T}_{\mathrm{g} 2}$ of GFRP bars decreased by $1.7 \%, 7.8 \%$, and $7.0 \%$, respectively, after aging at $60{ }^{\circ} \mathrm{C}$ for 183 days in SW, SA, and SWC environments. Thus, it is indicated that the resin conducts an irreversible reaction, but the resin bears mild corrosion as a whole.

FTIR was used to test the infrared spectra of GFRP bars that were aged in three environments at $60^{\circ} \mathrm{C}$ for 183 days and in non-aged state, as shown in Figure 8. It mainly tests the stretching vibration bands of $\mathrm{CH}$ and $\mathrm{OH}$ functional groups, and the peak-wave numbers of the stretching vibration bands of $\mathrm{CH}$ and $\mathrm{OH}$ approximate to $2900 \mathrm{~cm}^{-1}$ and $3500 \mathrm{~cm}^{-1}$, respectively. When the hydrolysis reaction of GFRP bars occurs, the peak strength of $\mathrm{OH}$ will increase, but that of $\mathrm{CH}$ will basically remain unchanged. It can be seen from Figure 8 that the hydrolysis degree of GFRP bars is the most conspicuous in SA environment, followed by SWC, and the weakest is SW. 


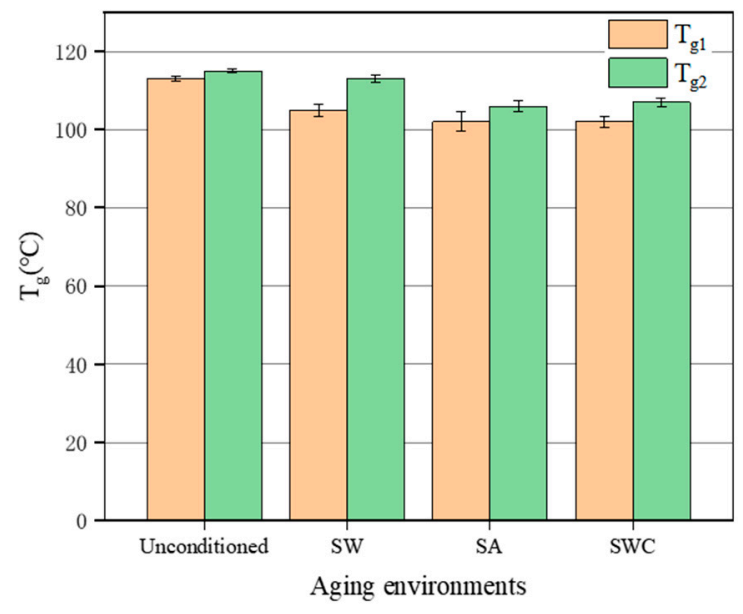

Figure 7. Comparison of $\mathrm{T}_{\mathrm{g}}$ of GFRP bars in different aging environments.

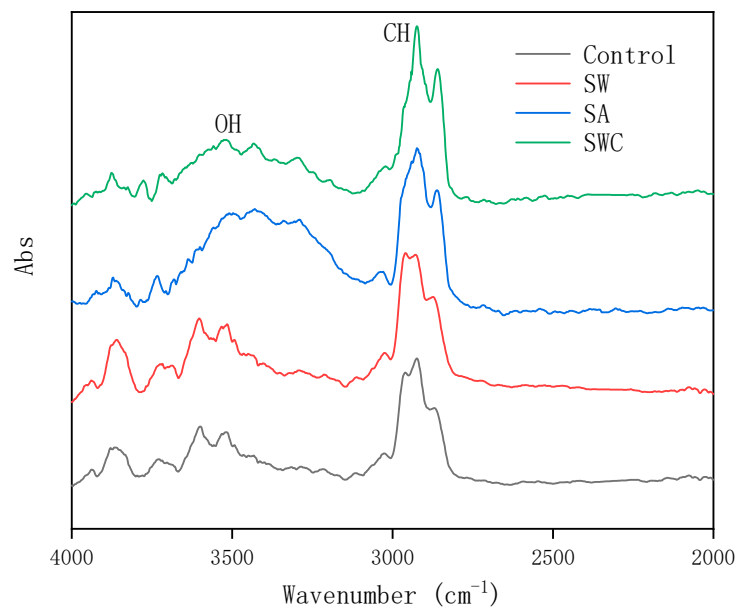

Figure 8. FTIR of GFRP bars.

\section{Long-Term Prediction Model of GFRP Bars}

The conventional prediction models for long-term mechanical properties of GFRP bars are mostly based on Arrhenius equation [21,22]. According to Arrhenius's theory, the relationships between strength, degradation rate, and temperature of GFRP bars is as follows [26]:

$$
\mathrm{k}=1 / \mathrm{t}=\mathrm{A} \exp \left(-\mathrm{E}_{\mathrm{a}} / \mathrm{RT}\right),
$$

where, $\mathrm{k}$ is degradation rate $(1 /$ time $), \mathrm{t}$ is degradation time, $\mathrm{A}$ is degradation constant, $E_{a}$ is activation energy of materials, $R$ is universal gas constant, and $T$ is the temperature in Kelvin (K).

The conversion of Equation (4) are as follows:

$$
\begin{gathered}
1 / k=t=\frac{1}{A} \exp \left(E_{a} / R T\right), \\
\ln (1 / k)=\ln t=E_{a} / R T-\ln A,
\end{gathered}
$$

The following three models are most used for predicting the long-term properties of GFRP bars:

$$
\begin{gathered}
\text { Model 1: } Y=a \log (t)+b, \\
\text { Model 2 : } Y=100 \exp (-t / \tau),
\end{gathered}
$$

Model 3: $\mathrm{Y}=\left(100-\mathrm{Y}_{\infty}\right) \exp (-\mathrm{t} / \tau)+\mathrm{Y}_{\infty}$, 
where $Y$ is strength retention; $t$ is time; $a, b$ and $\tau$ are fitting parameters; and $Y_{\infty}$ is strength retention of FRP bars at infinite aging time.

It was noted that Model 1 proposed by Litherland et al. [27] was used for predicting the durability of glass fiber concrete (GRC). Bank et al. [17] employed Model 1 to analyze the long-term mechanical properties of FRP composites. Manalo et al. [8] use this model to predict the relationship between the ILSS retention and aged time of GFRP bars in different environments. However, Model 1 also had the following limitations: (1) The model is fitted based on the experimental data without considering the degradation mechanism of materials; (2) The strength of FRP bars without aging is considered to be infinite in model 1, which is inconsistent with the fact; (3) The Arrhenius equation assumes that the degradation mechanism of materials does not change with temperature variation. However, the Arrhenius line obtained in many scholars' studies $[18,28]$ was not parallel, which violates the hypothesis. It was assumed in Model 2 and Model 3 that the main fracture mode of FRP bars proves to be the separation of fiber and resin interface, which is consistent with microscopic observation results [14,29]. Difference between the two models was whether the strength retention of materials becomes zero at infinite time. In other words, the strength retention of materials was considered to be zero in Model 2, while Model 3 assumes that the materials still retain some strength $\left(Y_{\infty}\right)$ at infinite time. It was proven that the $Y_{\infty}$ can exert a significant impact on accuracy of the model, and the values of $Y_{\infty}$ obtained by different researchers vary greatly [24,30]. Based on this, Model 2 was used in this study to establish the durability prediction model of GFRP bars in three environments.

In this paper, the long-term mechanical properties prediction model of GFRP bars in three accelerated aging environments (i.e., SA, SW, and SWC) was established in the following steps:

(1) The test data were fitted with Equation (8) to obtain fitting parameter (i.e., $\tau$ ) and the fitting curve is shown in Figure 9. Then, $\tau$ and correlation coefficients obtained were listed in Table 3.

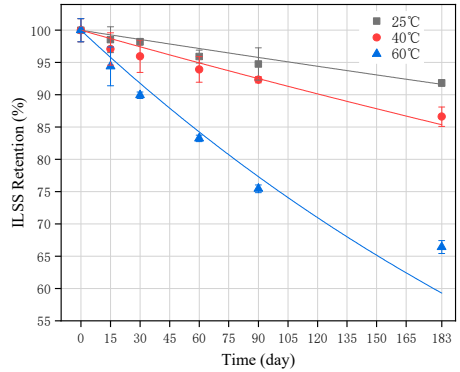

(a)



(b)

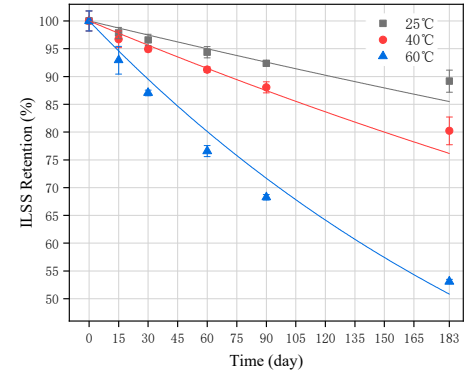

(c)

Figure 9. Fitting of long-term mechanical property test data for GFRP bars based on Model 2 in different environments: (a) SW; (b) SA; and (c) SWC.

Table 3. Data fitting of long-term mechanical property test for GFRP bars based on Model 2.

\begin{tabular}{ccccc}
\hline Environment & Temperature $\left({ }^{\circ} \mathbf{C}\right)$ & $\boldsymbol{\tau}$ & Fitted Equation & $\mathbf{R}^{\mathbf{2}}$ \\
\hline \multirow{3}{*}{ SW } & 25 & 2092 & $\mathrm{Y}=100 \exp (-\mathrm{t} / 2092)$ & 0.97 \\
& 40 & 1157 & $\mathrm{Y}=100 \exp (-\mathrm{t} / 1157)$ & 0.95 \\
& 60 & 350 & $\mathrm{Y}=100 \exp (-\mathrm{t} / 350)$ & 0.89 \\
\hline \multirow{3}{*}{$\mathrm{SA}$} & 25 & 733 & $\mathrm{Y}=100 \exp (-\mathrm{t} / 733)$ & 0.93 \\
& 40 & 478 & $\mathrm{Y}=100 \exp (-\mathrm{t} / 478)$ & 0.88 \\
& 60 & 189 & $\mathrm{Y}=100 \exp (-\mathrm{t} / 189)$ & 0.97 \\
SWC & 25 & 1167 & $\mathrm{Y}=100 \exp (-\mathrm{t} / 1167)$ & 0.88 \\
& 40 & 672 & $\mathrm{Y}=100 \exp (-\mathrm{t} / 672)$ & 0.94 \\
& 60 & 270 & $\mathrm{Y}=100 \exp (-\mathrm{t} / 270)$ & 0.97 \\
\hline
\end{tabular}


(2) Substitute $\tau$ into the Equation (8), making the strength retention $60 \%, 70 \%, 80 \%$, and $90 \%$, respectively. Then, the Arrhenius straight-line was fitted, as is shown in Figure 10, and the straight-line slope and correlation coefficient were listed in Table 4.

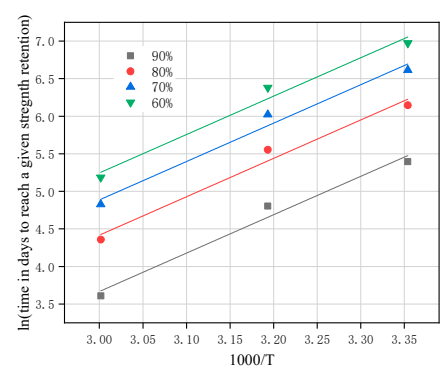

(a)

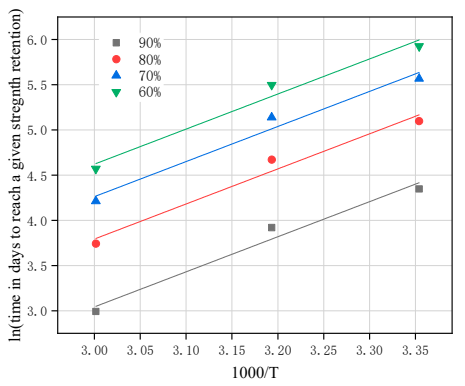

(b)

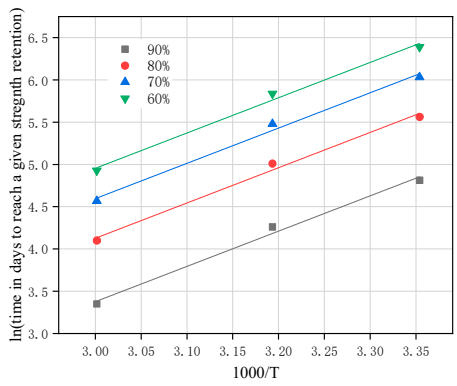

(c)

Figure 10. Arrhenius line for durability prediction model of GFRP bars in different environments: (a) SW; (b) SA; and (c) SWC.

Table 4. Fitting of Equation (6) for long-term mechanical property prediction of GFRP bars.

\begin{tabular}{ccc}
\hline Environment & $\mathbf{E}_{\mathbf{a}} / \mathbf{R}$ & $\mathbf{R}^{\mathbf{2}}$ \\
\hline SW & 5111 & 0.97 \\
SA & 3878 & 0.95 \\
SWC & 4173 & 0.98 \\
\hline
\end{tabular}

It was seen that the correlation coefficients $\left(R^{2}\right)$ of the regression equation in Equation (6) were not less than 0.95 , showing an accurate fitting; The obtained $E_{a} / R$ from high to low was from SW, SWC, and SA environments, which indicated that the strength degradation of GFRP bars in SW environment required more activation energy, which is consistent with the test results.

(3) The Arrhenius equation was used to obtain the time-shift factor (TSF) under different aging conditions.

TSF was introduced to compare the time that GFRP bars can reach the same degradation rate at different temperatures. If the strength degradation rates of GFRP bars maintain $k$ in the aging environment at temperature $T_{1}$ and $T_{2}$, the required time relationship was analyzed as follows, according to Equation (4):

$$
\begin{gathered}
\mathrm{k}=1 / \mathrm{t}_{1}=\mathrm{A} \exp \left(-\mathrm{E}_{\mathrm{a}} / \mathrm{RT}_{1}\right), \\
\mathrm{k}=1 / \mathrm{t}_{2}=\mathrm{A} \exp \left(-\mathrm{E}_{\mathrm{a}} / \mathrm{RT}_{2}\right), \\
\mathrm{TSF}=\frac{\mathrm{t}_{1}}{\mathrm{t}_{2}}=\exp \left[\frac{\mathrm{E}_{\mathrm{a}}}{\mathrm{R}}\left(\frac{1}{\mathrm{~T}_{1}}-\frac{1}{\mathrm{~T}_{2}}\right)\right],
\end{gathered}
$$

By using Equation (12) and taking the average temperature of $12.3^{\circ} \mathrm{C}$ offshore in the Yellow Sea area of China as an example, the TSF at different temperatures under three environments are listed in Table 5.

Table 5. TSF of GFRP bars at different temperatures.

\begin{tabular}{ccccc}
\hline Environment & $\mathbf{1 2 . 3}{ }^{\circ} \mathbf{C}$ & $\mathbf{2 5}{ }^{\circ} \mathbf{C}$ & $\mathbf{4 0}^{\circ} \mathbf{C}$ & $\mathbf{6 0}^{\circ} \mathbf{C}$ \\
\hline SW & 1 & 2.144 & 4.873 & 12.983 \\
SA & 1 & 1.784 & 3.326 & 6.995 \\
SWC & 1 & 1.864 & 3.644 & 8.110 \\
\hline
\end{tabular}

By using the data and test results in Table 5, the master curve of the long-term mechanical model of GFRP bars in offshore area of Yellow Sea of China (annual average 
temperature is $12.3^{\circ} \mathrm{C}$ ) was established, as shown in Figure 11, and the parameters of regression equation are listed in Table 6.

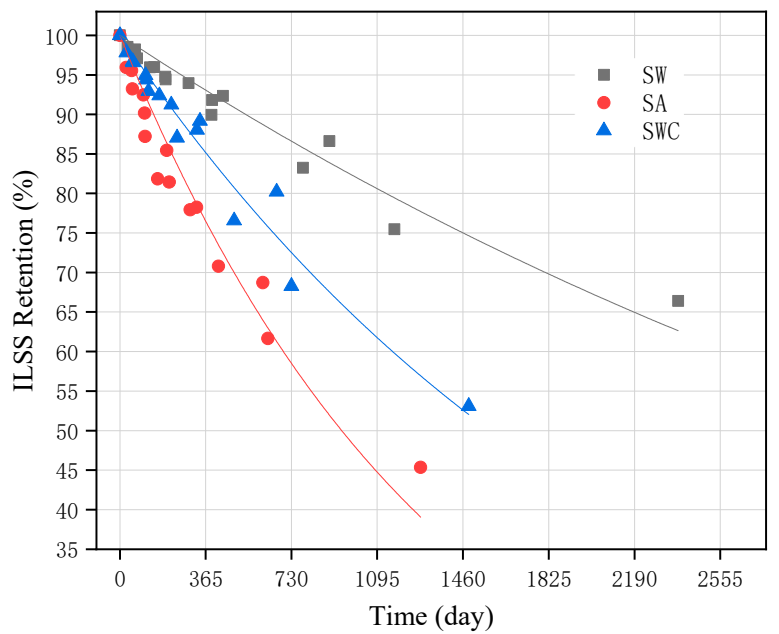

Figure 11. Master curve of long-term mechanical property degradation of GFRP bars in different environments at $12.3^{\circ} \mathrm{C}$.

Table 6. Main curve parameters of regression equation of long-term mechanical model of GFRP bars in the Yellow Sea area of China.

\begin{tabular}{ccc}
\hline Environment & $\boldsymbol{\tau}$ & $\mathbf{R}^{\mathbf{2}}$ \\
\hline SW & 5078 & 0.95 \\
SA & 1362 & 0.94 \\
SWC & 2272 & 0.96 \\
\hline
\end{tabular}

It was seen that the master curves matched well with the measured ILSS retention with correlation coefficients larger than 0.9 and can be used to predict the strength retention of GFRP bars serving in three environments (i.e., SA, SW, and SWC) tested in this study.

\section{Conclusions}

This paper explored the mechanical degradation law and mechanism of GFRP bars in different aging environments. The research results are as follows:

1. Under the same conditions, the strength degradation rate of GFRP bars was the fastest in SA environment, followed by SWC and then SW. It was seen that strong alkali environments (i.e., SA and SWC environments) caused serious damage to GFRP bars. The main reason is that the $\mathrm{OH}^{-}$radical reacts with $\mathrm{SiO}_{2}$ to degrade the glass fiber. The concrete in SWC environment had a certain protective effect, leading to less damage.

2. Under the three environments, the degradation rate of ILSS of GFRP bars mounts with the increase of temperature. The main reason for this phenomenon was that temperature increase could accelerate the hydrolysis reaction rate of GFRP bars. In the early stage of aging, water molecules quickly diffused to the GFRP bars, weakening the interfacial bonding ability of the resin and fiber, resulting in a significant decrease in ILSS. In the later stage of aging, as the GFRP bars become saturated, the rate of decrease in material strength slows down. Therefore, the strength degradation rate in the early stage was faster than that in the later stage.

3. The microstructures of the samples after accelerated aging for 183 days in three environments were observed. It was observed from the cross-sectional view that the sample fiber and resin were separated in varying degrees after aging in SA and SWC environments. This phenomenon was caused by different expansion degrees of resin matrix after water absorption, and the seepage pressure will also destroy the interface phase. Moreover, the resin produced a few holes, demonstrating that the resin eroded in the aging environment, but the overall properties were not affected much. It was seen in the longitudinal 
section micrograph that the fiber surface of samples was significantly damaged after aging in SA and SWC environments, and that samples in SW environment bear a little light aging damage.

4. DSC was applied to test $\mathrm{T}_{\mathrm{g}}$ of GFRP bars aged in three environments at $60{ }^{\circ} \mathrm{C}$ for 183 days. Compared with $\mathrm{T}_{\mathrm{g}}$ of ordinary samples, $\mathrm{T}_{\mathrm{g}}$ of GFRP bars decreased by $1.7 \%$, $7.8 \%$, and $7.0 \%$, respectively, in three environments. Thus, it indicated that the resin caused an irreversible reaction, which was consistent with the observation results of SEM. FTIR was used to test the infrared spectra of GFRP bars that were unconditioned and aged at $60{ }^{\circ} \mathrm{C}$ in three environments for 183 days. It was seen that the hydrolysis degree of GFRP bars was the most conspicuous in SA environment, followed by SWC, with the weakest in SW environment, which is consistent with the degradation law of mechanical properties, observation results of SEM, and analysis results of $\mathrm{T}_{\mathrm{g}}$ changes.

5. The master curve of long-term mechanical model of GFRP bars in the Yellow Sea area of China was established, which can predict the strength retention of GFRP bars serving in three environments.

Author Contributions: Conceptualization, W.L. and F.L.; methodology, W.L. and F.W.; software, Q.W. and H.L.; validation, F.L.; formal analysis, W.L. and M.Z.; investigation, W.L. and F.L.; resources, Y.J.; data curation, W.L. and F.L.; writing-original draft preparation, W.L., F.W. and M.Z.; writing-review and editing, W.L., F.W. and M.Z.; supervision, F.L. All authors have read and agreed to the published version of the manuscript.

Funding: This research was funded by Key R \& D Program of Shandong Province (International Scientific and Technological Cooperation) (grant number 2019GHZ015), by the Special Funds of the Central Government Guiding Local Science and Technology Development (grant number YDZX20193700004703).

Institutional Review Board Statement: Not applicable.

Informed Consent Statement: Not applicable.

Data Availability Statement: Data are contained within the article.

Conflicts of Interest: The authors declare no conflict of interest.

\section{References}

1. Jiang, L.; Xu, J.; Zhu, Y.; Mo, L. Influence of chloride salt type on threshold level of reinforcement corrosion in simulated concrete pore solutions. Constr. Build. Mater. 2012, 30, 516-521. [CrossRef]

2. Soriano, C.; Alfantazi, A. Corrosion behavior of galvanized steel due to typical soil organics. Constr. Build. Mater. 2016, 102, 904-912. [CrossRef]

3. ACI (American Concrete Institute). Guide for the Design and Construction of Structural Concrete Reinforced with Fiber-Reinforced Polymer (FRP) Bars; ACI Committee 440, Report 440.1R-15; American Concrete Institute: Farmington Hills, MI, USA, 2015.

4. Arczewska, P.; Polak, M.A.; Penlidis, A. Degradation of glass fiber reinforced polymer (GFRP) bars in concrete environment. Constr. Build. Mater. 2021, 293, 123451. [CrossRef]

5. Duo, Y.; Liu, X.; Liu, Y.; Tafsirojjaman, T. Environmental impact on the durability of FRP reinforcing bars. J. Build. Eng. 2021, 43, 102909. [CrossRef]

6. Al-Salloum, Y.A.; El-Gamal, S.; Almusallam, T.; Alsayed, S.; Aqel, M. Effect of harsh environmental conditions on the tensile properties of GFRP bars. Compos. Part B Eng. 2013, 45, 835-844. [CrossRef]

7. El-Hassan, H.; El-Maaddawy, T.; Al-Sallamin, A.; Al-Saidy, A. Durability of glass fiber-reinforced polymer bars conditioned in moist seawater-contaminated concrete under sustained load. Constr. Build. Mater. 2018, 175, 1-13. [CrossRef]

8. Manalo, A.; Maranan, G.; Benmokrane, B.; Cousin, P.; Alajarmeh, O.; Ferdous, W.; Liang, R.; Hota, G. Comparative durability of GFRP composite reinforcing bars in concrete and in simulated concrete environments. Cem. Concr. Compos. 2020, 109, 103564. [CrossRef]

9. Benmokrane, B.; Ali, A.H.; Mohamed, H.M.; ElSafty, A.; Manalo, A. Laboratory Assessment and Durability Performance of Vinyl-ester, Polyester, And Epoxy Glass-FRP Bars for Concrete Structures. Composites 2017, 114, 163-174. [CrossRef]

10. Chen, Y.; Davalos, J.F.; Ray, I.; Kim, H.-Y. Accelerated aging tests for evaluations of durability performance of FRP reinforcing bars for concrete structures. Compos. Struct. 2007, 78, 101-111. [CrossRef]

11. Koller, R.; Chang, S.; Xi, Y. Fiber-reinforced bars under freeze-thaw cycles and different loading rates. J. Compos. Mater. 2007, 41, 5-25. [CrossRef] 
12. Robert, M.; Benmokrane, B. Combined effects of saline solution and moist concrete on long-term durability of GFRP reinforcing bars. Construct. Build. Mater. 2013, 38, 274-284. [CrossRef]

13. Morales, C.N.; Claure, G.; Emparanza, A.R.; Nanni, A. Durability of GFRP reinforcing bars in seawater concrete. Constr. Build. Mater. 2021, 270, 121492. [CrossRef]

14. Khatibmasjedi, M.; Ramanathan, S.; Suraneni, P.; Nanni, A. Durability of commercially available GFRP reinforcement in seawater-mixed concrete under accelerated aging conditions. J. Compos. Constr. 2020, 24, 04020026. [CrossRef]

15. Fergani, H.; Di Benedetti, M.; Oller, C.M.; Lynsdale, C.; Guadagnini, M. Durability and degradation mechanisms of GFRP reinforcement subjected to severe environments and sustained stress. Constr. Build. Mater. 2018, 170, 637-648. [CrossRef]

16. Montaigu, M.; Robert, M.; Ahmed, E.A.; Benmokrane, B. Laboratory characterization and evaluation of durability performance of new polyester and vinylester E-glass GFRP dowels for jointed concrete pavement. J. Compos. Constr. 2013, 17, 176-187. [CrossRef]

17. Bank, L.C.; Gentry, T.R.; Thompson, B.P.; Russell, J.S. A model specification for composites for civil engineering structures. Constr. Build. Mater. 2003, 17, 405-437. [CrossRef]

18. Wu, G.; Dong, Z.-Q.; Wang, X.; Zhu, Y.; Wu, Z.-S. Prediction of long-term performance and durability of BFRP bars under the combined effect of sustained load and corrosive solutions. J. Compos. Constr. 2015, 19, 04014058. [CrossRef]

19. Robert, M.; Cousin, P.; Benmokrane, B. Durability of GFRP reinforcing bars embedded in moist concrete. J. Compos. Constr. 2009, 13, 66-73. [CrossRef]

20. Lu, C.; Ni, M.; Chu, T.; He, L. Comparative Investigation on Tensile Performance of FRP Bars after Exposure to Water, Seawater, and Alkaline Solutions. J. Mater. Civ. Eng. 2020, 32, 04020170. [CrossRef]

21. Wang, Z.; Zhao, X.L.; Xian, G.; Wu, G.; Raman, R.S.; Al-Saadi, S. Durability study on interlaminar shear behaviour of basalt-, glass- and carbon-fibre reinforced polymer (B/G/CFRP) bars in seawater sea sand concrete environment. Construct. Build. Mater. 2017, 156, 985-1004. [CrossRef]

22. Canadian Standards Association (CSA). Specification for Fibre-Reinforced Polymers (CAN/CSA S807-19); CSA: Rexdale, ON, Canada, 2019.

23. ASTM Standard ASTM D4475-02; Standard Test Method for Apparent Horizontal Shear Strength of Pultruded Reinforced Plastic Rods by the Short-Beam Method (ASTM D4475-02 (2016)). ASTM International: West Conshohocken, PA, USA, $2016 ;$ p. 19103.

24. Chen, Y. Accelerated Ageing Tests and Long-Term Prediction Models for Durability of FRP Bars in Concrete. Ph.D. Dissertation, West Virginia University, Morgantown, WV, USA, 2007.

25. ASTM Standard ASTM D3418-08; Standard Test Method for Transition Temperatures and Enthalpies of Fusion and Crystallization of Polymers by Differential Scanning Calorimetry. ASTM: West Conshohocken, PA, USA, 2012.

26. Nelson, W. Accelerated Testing-Sustained Models, Test Plans, and Data Analyses; Wiley: New York, NY, USA, 1990.

27. Litherland, K.L.; Okley, D.R.; Proctor, B.A. The use of accelerated aging procedures to predict the long term strength of GRC composites. Cem. Concr. Res. 1981, 11, 455-466. [CrossRef]

28. Gonenc, O. Durability and Service-life Prediction of Concrete Reinforcing Materials. Master's Thesis, University of WisconsinMadison, Madison, WV, USA, 2001.

29. Kamal, A.S.M.; Boulfiza, M. Durability of GFRP rebars in simulated concrete solutions under accelerated aging conditions. J. Compos. Constr. 2011, 15, 473-481. [CrossRef]

30. Wang, Z.; Zhao, X.-L.; Xian, G.; Wu, G.; Raman, R.S.; Al-Saadi, S.; Haque, A. Long-term durability of basalt- and glass-fibre reinforced polymer (BFRP/GFRP) bars in seawater and sea sand concrete environment. Constr. Build. Mater. 2017, 139, 467-489. [CrossRef] 